\title{
A Customer Knowledge Management Model for Local Hospitality on European Market in Western China
}

\author{
Liu Xuelian \\ School of Tourism and Economic Management \\ Chengdu University, 610106
}

\begin{abstract}
Customer knowledge has increasingly importance in customer-oriented enterprise. Customer knowledge management models can help managers to find the real value chain in business. Compared with international hotel, local hotel has less advantage in marketing and customer service in Western China. The research employed the IC process model to identify the internal resources of CKM for local hotel in western China. Through four steps, researcher proposed an applicable customer knowledge management model to help local hotel better understand European customers by monitor the related indicators. This model can help local hotel to increase their market share of the inbound market in western China.
\end{abstract}

Keywords-Customer knowledge, Intellectual capital, Hospitality, European market, Western China, Customer knowledge management model

\section{INTRODUCTION}

\section{A. Research background}

Tourism in China has seen a rapid development since the adoption of an open-door economic reform policy in 1978. In terms of international tourism, China has enjoyed the fastest growth in inbound tourism in the last decade and consequently, such trends will develop in the years to come. As a unique and interesting destination, China is a major factor in the future development of regional tourism throughout Asia, as well as throughout the world. According to the report by World Tourism Organization (WTO), China has been placed within the top ten international ranking for international destinations.

As one of most important part of tourism industry, the hardware of a local hotel in China, such as rooms, facilities, decoration and its luxury index, has been internationalized, but some software, such as hotel management and culture, still have big gaps within the international hotel brand. Therefore, compared with an international hotel, a local hotel has to remain within the low market share in the inbound tourist market. These local hotels have to face competition with international chains of hotels. Consequently, when compared with local hotels, global hotel chains have more advantages in:
A. Brand recognition;
B. Management Advantage;
C. Globalization Online Booking Systems;
D. Staff Training system

These local hotels have less advantage in marketing and customer service. Therefore, many local hotels have to focus on the domestic market. However, most local hotels are not willing to give up the high-profit market, such as the European market, and they are expecting to increase their share of the inbound market. This research focuses on improving local hotels performance in European market.

\section{B. Research problems statement}

The local hotels have reached international standard from a hardware context, but as with all customer-oriented enterprises, these hotels also face many problems in management that are hard to resolve. To increase the share of the European market, local hotels need to resolve a number of problems.

The problem can be identified that there are cross-culture knowledge gaps between the customer and hotels in expectation, perception and satisfaction. These problems can be defined as follows:

\section{Problem 1.}

The first problem concerns the knowledge gap between customers' expectations and knowledge possessed by the enterprise. (Gap1 in Fig. 1)

The problem exists in many businesses, but it is far more serious in cross-cultural hospitality. Tourist product designers have not gained enough cross-cultural knowledge about customers, so they cannot design appropriate standards for hotel products and services to meet with the customers' expectations.

\section{Problem 2.}

The second problem concerns the knowledge gap between customers' perceptions of products and services supplied by the enterprise. (Gap2 in Fig. 1)

This problem has led to customers not fully understanding or appreciating the products and services offered by the hotel, regardless as to how good the products are. It has meant that hotels have not been able to provide the essential cross-culture 
knowledge for customers to understand the value of the products and services on offer.

\section{Problem 3.}

The third problem concerns the knowledge gap between the effective factors of customer satisfaction and the knowledge mastered by the enterprise. (Gap3 in Fig. 1)
This problem is caused as a result of the poor quality methods of capturing and retaining customer feedback. Hotels cannot obtain effective cross-cultural customer knowledge from the customer directly (face to face communication, questionnaire or calling back) or indirectly (weblog or diary) and the result is that hotels lose the best chance to improve their standard of products and services.

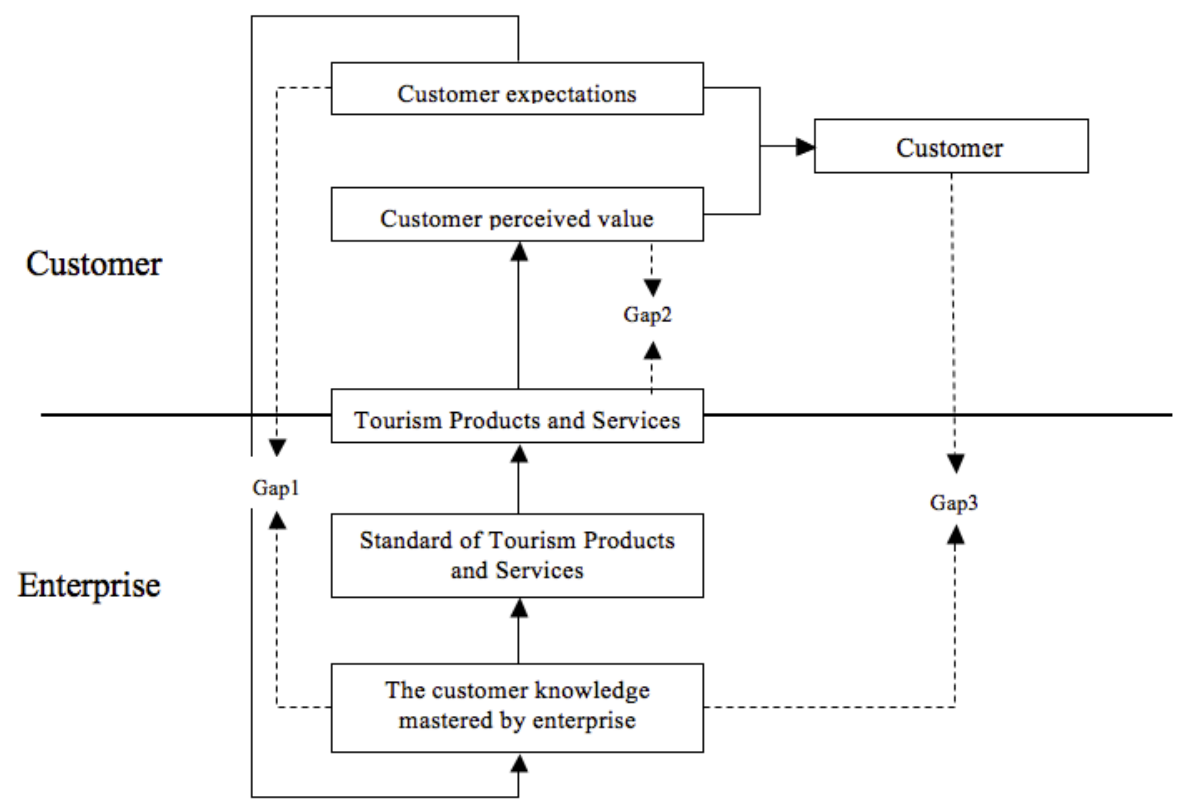

Fig. 1. Knowledge gap between customer and enterprise

These issues can be solved with customer knowledge management (CKM). Customer knowledge is viewed as an important asset for business. It needs to be managed by enterprises. Customer knowledge management (CKM) is the application of knowledge management (KM) instruments and techniques to support the exchange of knowledge between an enterprise and its customers [1]. Through CKM, an organization may obtain vital knowledge, adding an extra dimension to marketing research activity and improving customer service.

\section{RESEARCH METHODOLOGY}

This research employed qualitative methodology. The research methods include interview, content analysis, thematic extraction and comparison analysis.

\section{A. Stakeholder Identification}

Stakeholders to affect the organization and their views must be used as factors to be considered when making decisions. However, not all stakeholders to maintain consensus on all issues, including some groups than others more influential group, which is how to balance the interests of all parties to develop a strategy to consider the key issues. To manage customer knowledge in hotel industry, the stakeholder analysis is also an important step to identify the strategy.
The breakdown from multiple dimensions to the idea of the stakeholders of the enterprise greatly deepened people's awareness of the stakeholders. However, these classifications generally stay in the collegiate studies, lack of interoperability, thereby constraining the stakeholder theory, practical application.

The content analysis and thematic extraction are used to analyze the knowledge transcripts. These qualitative methods provide an identification of the stakeholders of local hotel. The expected output of this step is to identify an initial list of stakeholders for local hotel in western China.

The stakeholder groups of each organization represent a wide and diverse range of interests, given each stakeholder group has its own unique set of expectations, needs, and values. The most common way of classifying stakeholders is to consider groups of people with a distinguishable relationship with corporations ${ }^{[2]}$. The objectives of this step are to analyze the roles of the stakeholders.

The researcher will be applied Mitchell score method to analyze the roles of the stakeholders. Mitchell and Wood proposed a score method (score-based approach) to classify stakeholders, which is clear, simple and easy. Mitchell and others defined three attributes of potential stakeholders scores, then determined what type of stakeholder according to the level of score ${ }^{[3]}$. The three properties are: (1) the legitimacy 
which is endowed with a group or a specific request for the corporate legal and moral right on; (2) The powers that is a whether groups have influence corporate decision-making status, ability and corresponding means; (3) urgency. The scoring method proposed by Mitchell greatly improves the classification of stakeholders' operability. Fig. 2 shows the details of Mitchell score method.

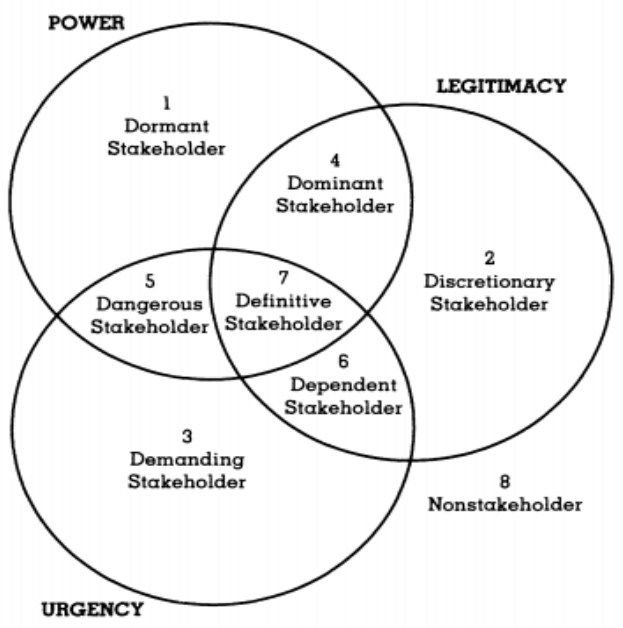

Fig. 2. Mitchell score method

In this research, Mitchell score method is employed to identify definitive stakeholder, which is defined as key stakeholder. The researcher will interview the initial stakeholder to collect data to identify key stakeholders. Above initial stakeholders will be invited to attend the interview.

\section{B. Strategy formulation}

Base on the intellectual capital process, the next step is forming the business concept ${ }^{[4]}$. Business concept in this research is related to identify the CKM strategy for local hotel in western China. For strategy identification, the key stakeholders' needs and expectations of CKM in local hotel would be the basement and source for the strategy. An interview is conducted with the selected experts who are representative for all key stakeholder groups. In this step, the researcher will formulate the practical strategies by using content analysis, thematic extraction, and comparison analysis.

\section{Key Success Factor identification}

The next step of the process is to translate the strategies into action plans that are related with key success factors. The strategies formulated in the previous step must be used to identify the Key Success Factors (KSFs). In each strategy, there must be KSFs to reach these strategies. It needs transform knowledge existing in hotel experts by interview them.

\section{Indicator identification}

The next step of the IC process model is to develop a measurement for each key success factor by identifying indicators. The measurement is to identify knowledge components of an organization in order to manage them so they can continually improve their performance. Indicator identification is very difficult for the indicators must be reflected KFSs drastically. However, appropriate indicators could be selected elaborately and carefully. In most cases, for each KFS, more than one indicator is needed to get a clear and correct picture ${ }^{[4]}$.

The methodology of literature review and interview will be used to select indicators.

\section{RESULTS AND ANALYSIS}

\section{A. Stakeholder Identification}

The result of this step is the initial list of stakeholders. By using content analysis method, the stakeholders formulized to 12 groups, it is clear that the stakeholders including:

TABLE I. INITIAL LIST OF STAKEHOLDER

\begin{tabular}{ll}
\hline Stakeholder Types & Initial list of stakeholder \\
\hline Government & Government \\
Regulatory & \\
Political groups & \\
Owner & Owner \\
Investors & \\
Shareholders, & \\
Stockholders & \\
Customer & Customer \\
Consumers & \\
Consumer advocacy groups & \\
Unions & Unions \\
Employees & Employees \\
Managers & \\
Top management & \\
Industry association & Top management \\
Trade associations & Industry associations \\
Competitors & \\
Suppliers & Competitors \\
Local community & Suppliers \\
Community & Community \\
Financial community & \\
Activist groups & \\
Intermediaries & \\
Media & Intermediaries \\
\hline
\end{tabular}


For the perspective of the research is customer knowledge management, the key stakeholders are selected regard as the relationship of customer knowledge management. The stakeholders were analyzed to identify the role of the stakeholders.

The analyzing of stakeholder based on Mitchell score method. The scores are recorded in three attributes: power, legitimacy and urgency.

Base on Mitchell method, the stakeholders divided into three groups: definitive stakeholders, latent stakeholders and expectant stakeholders. They constituted various stakeholders on the development of the hotel business.

In this research, the definitive named as key stakeholder, whose salience will be high where all three of the stakeholder attributes-power, legitimacy, and urgency-are perceived by experts as present above. The stakeholders can provide support to the hotel differently depending on what they have and what they are capable of. The six key stakeholders have been selected based on who are playing the most important role to the hotel's CKM.

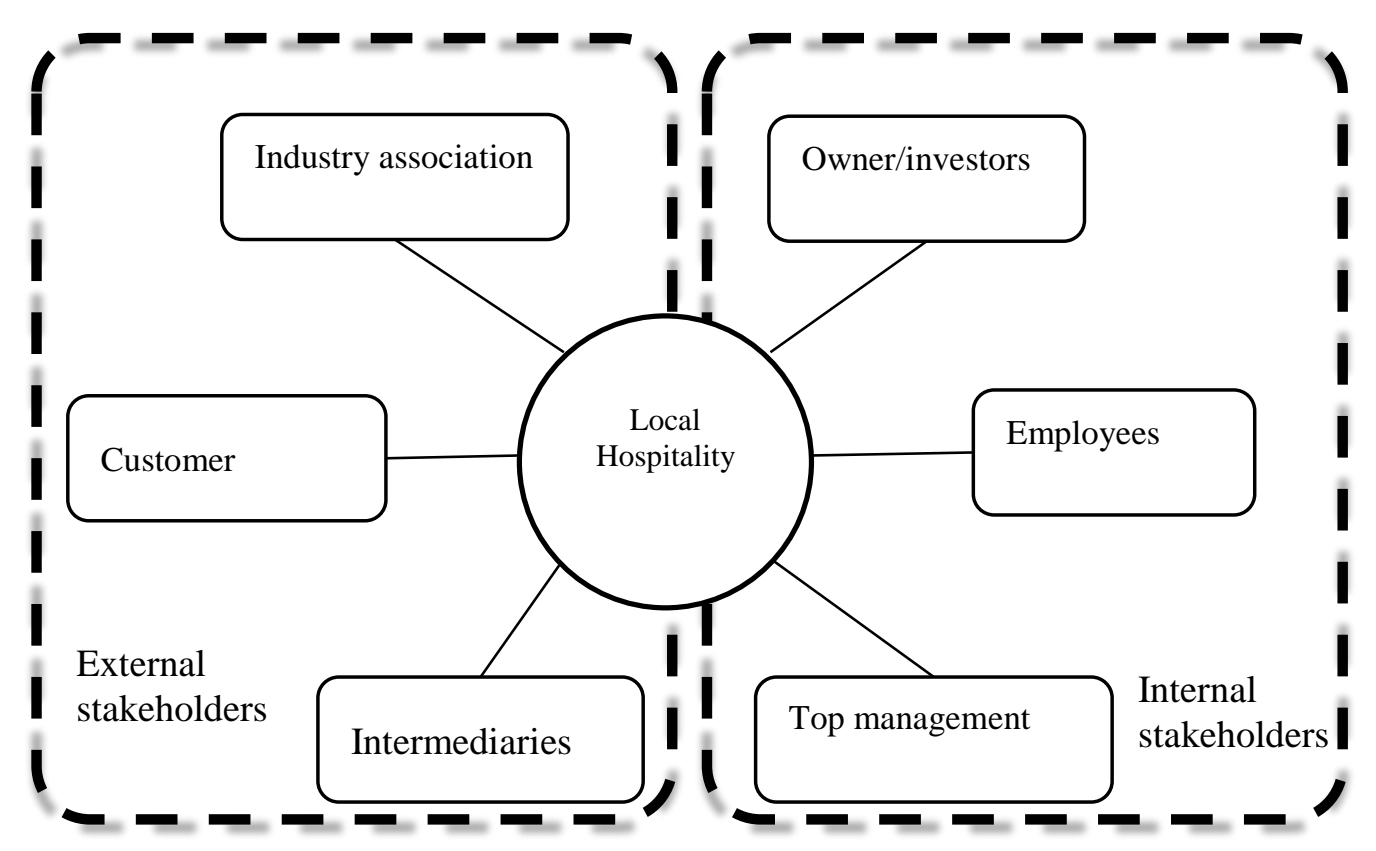

Fig. 3. Key stakeholders of local hotel

\section{B. Strategy formulation}

These five main ideas from the stakeholders' needs and expectations of managing customer knowledge would be fundamental concept to create CKM strategies which are statements that defines the future and identity for local hotel. Thus, sixteen needs and expectations from the stakeholders have been identified, grouped and categorized into five strategies:
First strategy (S1): Support cross-cultural customer knowledge management

Second strategy (S2): Brand marketing

Third strategy (S3): Improve service quality by CKM

Forth strategy (S4): Qualified staffs with cross-cultural knowledge

Fifth strategy (S5): Develop and maintain good relationship with customers.

TABLE II. STRATEGY FORMULATIONS

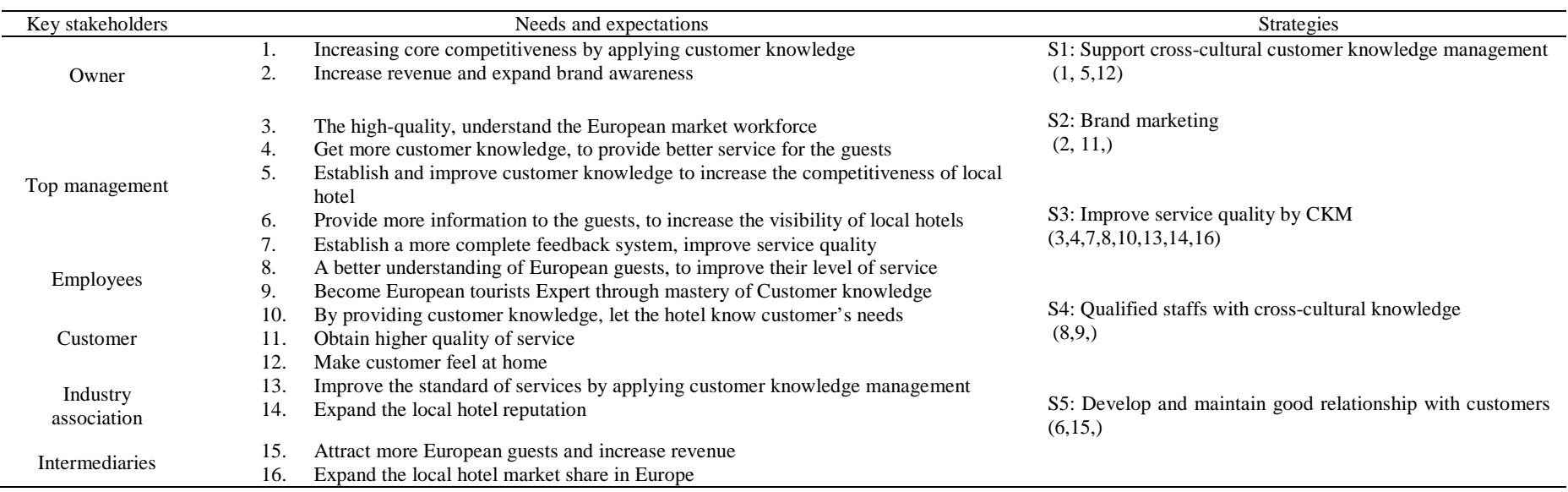


In order to develop strategies and identify related issues, an organization should consult with targeted groups of stakeholders. The consultation provides a better environment to facilitate debate and develop more equitable strategies. The stakeholders' needs and expectations are fundamental input factors to develop the strategies.

Therefore, the precise five strategies have been formulated. The strategies, which are formed by the local hotel's stakeholders, can respond more direct to any situation. The organization needs to have a clear and transparent structure and process to keep stakeholders and their consultation focused. In addition, the stakeholders can formulate strategies by sharing and participating from the beginning.

\section{Key Success Factor identification}

Based on the review hotel management document, researcher interviewed these key stakeholders about key success factor (KSF) according to research aim and formulated strategy. The key stakeholder selected the most appropriate success factors from above step. The researchers will count the number of the key stakeholders who are agreeing with the success factors. The success factors that reached a score of more than $50 \%$ of the key stakeholders will be selected as KSF. The key stakeholders have verified fourteen KSFs as follows:

I. First strategy (S1): to Support cross-cultural customer knowledge management, the key success factors were:

S1K1: Financial support

S1K2: Policy support

S1K3: Cross-cultural customer knowledge platform

II. Second strategy (S2): Brand marketing, the key success factors were:

S2K1: Advertisement

S2K2: Networking

III. Third strategy (S3): to improve service quality by $\mathrm{CKM}$, the key success factors were:

S3K1: Booking service

S3K2: Reception service

S3K3: Food and beverage service

S3K4: House keeping service

S3K5: Other services

IV. Fourth strategy (S4): qualified staffs with crosscultural customer knowledge, the key success factors were:

S4K1: Cross-cultural training

S4K2: Cross-cultural activities

V. Fifth strategy (S5): to develop and maintain good relationship with customers, the key success factors were:

S5K1: Communication with customers

S5K2: Customer relationship maintain

In this step, the expert panel can put the strategies into practice. The experts, who are from key stakeholders, have identified and verified the key success factor of each strategy. As a result, the hotels' customer knowledge management has specific actions to reach goals. This step of the process creates some opportunities to fix the problems within an organization using identified strategies which otherwise would be forgotten due to the focus primarily on their short-term goals ${ }^{[4]}$. Experts have verified the $14 \mathrm{KSFs}$.

\section{Indicator identification}

There are two scours of appropriate indicators list. One is from literature; another source of indicators is the Classification \& Accreditation for Star-rated Tourist Hotels by The National Standard of the People's Republic of China (GB/T 14308-2010). This document gives many practicable measurements from hotel hardware facilities to hotel services. Researcher select customer knowledge related indicators from the document combine with above list to form the possible indicator list.

The researcher makes a list of possible indicators (basis on above two sources) for the key stakeholder; some indicators are modified to suitable for this research for better understanding. The key stakeholder then selected the most appropriate indicators from the list. The researcher then counted the number of the stakeholders who agree to the indicators. The indicators, which received a score of more than fifty per cent of the experts, will be selected as the KSFs' indicators. Finally, the indicators of the key success factors are identified.

Then the experts' selected 50 indicators for measuring 14 key success factors.

This step presents the results of indicator selection. From the results it can be found that the measurement of each factor is clear and practical. The aim of measuring is to identify the knowledge component of and organization in order to manage them so they can continually improve their performance. The customer knowledge is difficult to measure so the idea is exploiting the measurement advantage of IC to make customer knowledge measurable. So the selection of indicator is one of the most important steps since it affecting the measurement process from concepts to practice.

\section{E. defining Intellectual Capital for local hotel}

In this step, the new indicators list link to IC as Table III. 
TABLE III. THE FORM FOR RE-DEFINING INTELLECTUAL CAPITAL FOR LOCAL HOTEL

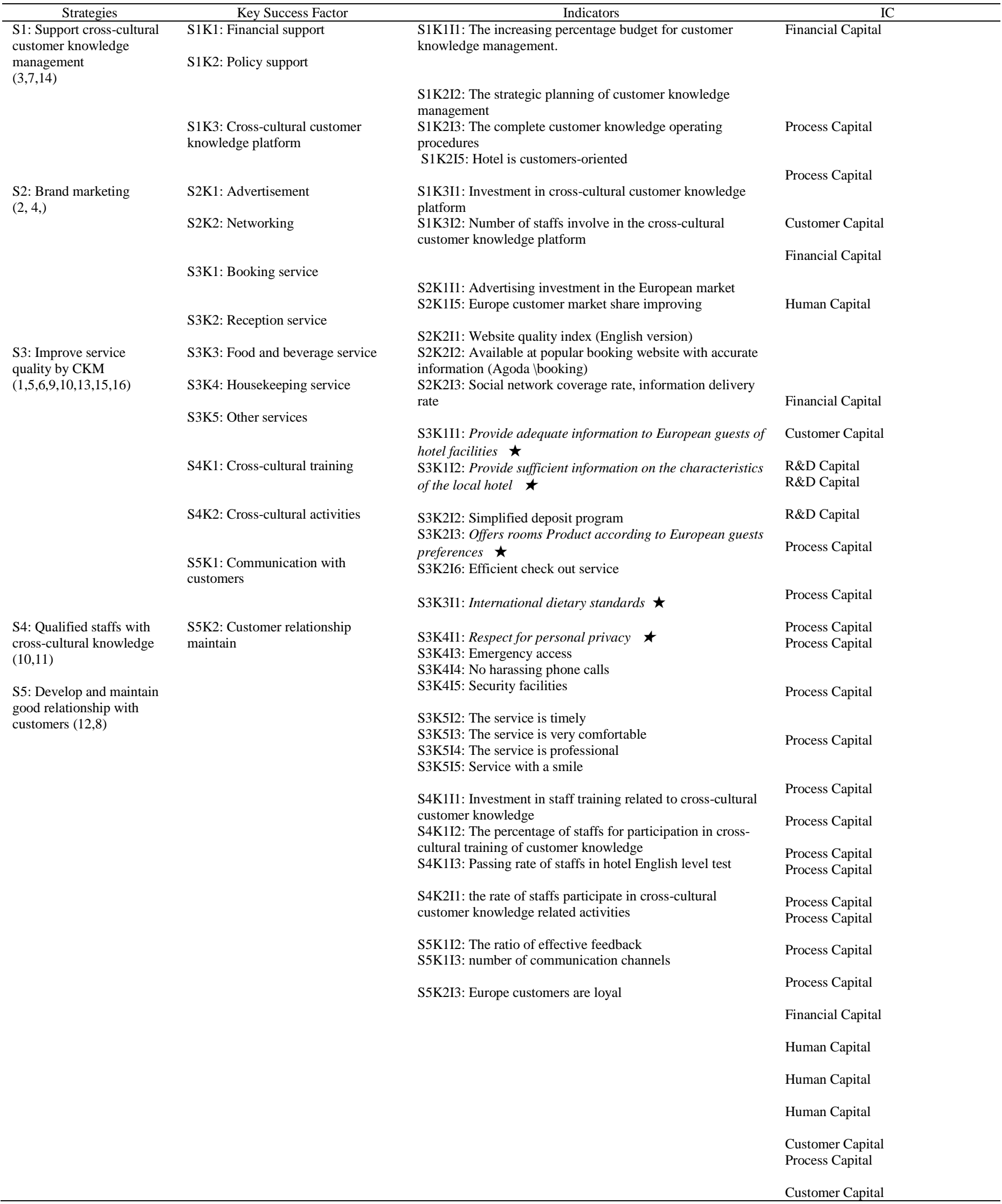


From this table, the relationship between KSFs, indicators and intellectual capital is established. This is the base of new IC model for CKM. The research weighs the intellectual capitals in percentage by indicators for local hotel in western China. According to the indicator new arrangement, 4 indicators related to financial capital can be weighted in percentage term at $12 \%$ of the local hotel's intellectual capital,
4 indicators related to human capital can be weighted at $12 \%$, 18 indicators related to process capital can be weighted at $56 \%, 3$ indicators related to customer capital can be weighted at $10 \%$ and 3 indicators related to renewal and development capital can be weighted at $10 \%$.

The new CKM model based on IC model for local hotel has been present as follows:
Customer Capital

S1K2I5: Hotel is customers-oriented

S5K2I3: Europe customers are loyal

S2K1I5: Europe customer market

share improving

Human Capital

S1K3I2: Number of staffs

involve in the cross-cultural

customer knowledge platform

S4K1I2: The percentage of staffs

for participation in cross-cultural

training of customer knowledge

S4K1I3: Passing rate of staffs in

hotel English level test

S4K2I1: the rate of staffs

participate in cross-cultural

customer knowledge related

activities
Financial Capital

S1K1I1: The increasing percentage budget for customer knowledge management.

S1K3I1: Investment in cross-cultural customer S2K1I1: Advertising investment in the European market

S4K1I1: Investment in Staff training related to crosscultural customer knowledge

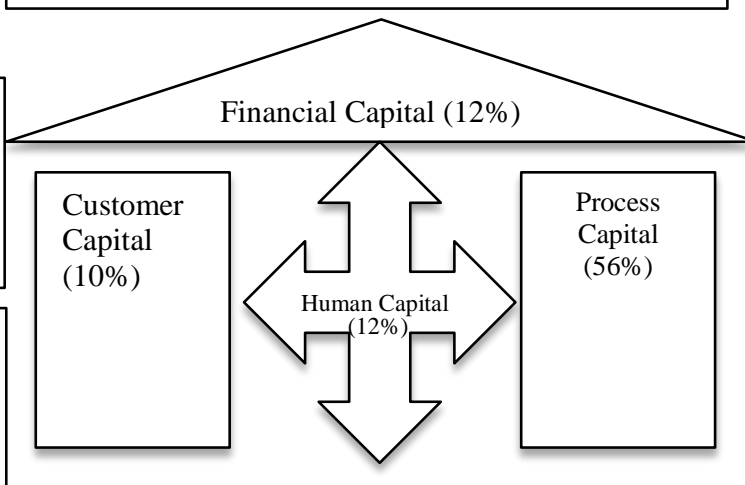

Renewal and Development Capital (10\%)

Renewal and Development Capital

S2K2I1: Website quality index (English version)

S2K2I2: Available at popular booking website

with accurate information (Agoda \booking)

S2K2I3: Social network coverage rate,

information delivery rate
Process Capital

S1K2I1: The number of customer knowledge management policies. S1K2I2: The strategic planning of customer knowledge management. S1K2I3: The complete customer knowledge operating procedures S3K1I1: Provide adequate information to European guests of hotel facilities

S3K1I2: Provide sufficient

information on the characteristics of the local hotel

S3K2I2: Simplified deposit program

S3K2I3: Offers rooms Product according to European guests

preferences $\star$

S3K2I6: Efficient check out service

S3K3I1: International dietary

standards

S3K4I1: Respect for personal privacy $\star$

S3K4I3: Emergency access

S3K4I4: No harassing phone calls

S3K4I5: Security facilities

S3K5I2: The service is timely

S3K5I3: The service is very

comfortable

S3K5I4: The service is professional

S3K5I5: Service with a smile

S5K1I3: number of communication channels

Fig. 4. IC model of CKM in local hospitality 


\section{F. CKM model}

The CKM model combined IC model and CK showing above. By using this model, it is easy to get the whole picture of customer knowledge management situation of a hotel; also it is easy to find shortage and disadvantage of customer knowledge management.

With different type of IC and its indicators, all four kind of CK can be monitored. Specifically, this model has the following characteristics:

\section{1) Dynamic}

This is a dynamic model for monitoring customer knowledge management problems. It involves all aspects of hotel management; also, this model is the innovative combination of customer knowledge and IC. Hotel can be guide to effectively manage the internal resources investigation in customer knowledge management.

\section{2) Immediacy}

This model can reflect current issues that exist in the hotel's customer knowledge management, and quickly trace the root of the problem.

\section{3) Comprehensive}

In local hotel in western China, the customer knowledge is random, scattered distribute in each hotel, so problem of customer knowledge is hard to be found and resolved. This model can comprehensively reflect the hotel's customer knowledge management issues, and clearly reflected in the hotel's internal resources. This model is based on customer knowledge management needs; help hotel manager to invest the internal resources to right place and monitor the performance better. Indicators of this model include direct and indirect categories, channels involving statistical data and customer feedback within the hotel, so the hotel can fully aware the customer knowledge management issues.

\section{4) Operability}

The model has 32 indicators, including direct and indirect indicators of each 16. Direct statistical indicators are easy to collect from management of the hotel, indirect indicators of customer data needs to be collected from customer feedback. With regular customer feedback, hotel can quickly find customer knowledge management issues. Therefore, this model is easy to operate in practice.

\section{CONCLUSION}

Tourism enterprises, especially in the hotel business, both systematic explicit knowledge and tacit knowledge are quite fragmented. In practice, they have not been effectively applied with truly full potential. If those $25 \%$ of new knowledge and apply timely conversion of industrial practice, then the tourism industry will have a fundamental change ${ }^{[5]}$.

Especially, tacit knowledge dissemination is considerable difficulties in hotel. There are many causes for this problem. Besides knowledge itself invisible and difficult to obtain, and the high cost of transfer time is difficult to assess, the "standardized management paradigm," have profound impact in hotel industry.
Highly rigid "standardized" bureaucratic organizational structure allows hotel lack of competitive advantage. Meanwhile in the traditional tourism enterprise management, innovation and tacit knowledge sharing activities have been bound by a " top-down" information paradigm, the core assumptions of this paradigm is the " information and knowledge only can be effectively treated through branches of trees formula structure ${ }^{[6]}$ ". So despite front-line staffs having a large number of tacit knowledge from direct customer service, the knowledge cannot be quickly transferred to senior management throughout the channels in enterprise. The explicit knowledge disseminate by senior managers through the process seriously lags behind changes of customer demand.

In fact, the knowledge flow is multi-directional. The knowledge either flows from top management to front-line staff, or vice versa. The knowledge also flows from customers to enterprise. The deeper understanding of knowledge flow can lead to better exploitation of knowledge and better performance of the enterprise in market.

In this study, in order to solving the low market share problem in European market for local hotel, the researcher proposed the CKM model to strength the management of customer knowledge, it can improve the hotel's service quality for European tourists and attract more European tourists. This model can improve customer knowledge management by analysis and monitor the knowledge creation and transfer process.

CKM model has been created by intellectual capital process. The intellectual capital process is adapted and modified so that the cultural context can be used beyond its original approach in the business sector. This is an original approach where an intellectual capital system of creating an IC system to manage the customer knowledge for local hotels in western China. The research employed the IC process model to identify the internal resources of the hotel; this is the first time use of IC process model in the local hotel in western China. Through four steps, researcher proposed an applicable IC model of customer knowledge management for local hotel in western China. This model provides an example for the future intellectual capital research of local hotels.

The CKM model can be used not only in local luxury hotel industry in western China, but also can be used in all type hotels that are catering European customers.

\section{REFERENCES}

[1] Gebert, H. et al., 2003. Knowledge-enabled customer relationship management: integrating customer relationship management and knowledge management concepts. Journal of Knowledge Management, 7(5), pp.107-123

[2] Personal, M. et al., 2010. The Importance of Strategic Stakeholder Management in Tourism Sector: Research on Probable Applications. Munich Personal RePEc Archive, 23(25308), pp.97-108.

[3] Mitchell, R.K., Agle, B.R. \& Wood, D.J., 1997. Toward a theory of stakeholder identification and salience: defining the principle of who and what really counts. Academy of Management Review, 22(4), pp.853-886.

[4] Roos, J. et al., 1997. Intellectual capital, London: Macmillan Business. 
[5] Zhao, W., Ritchie, J.R.B. \& Echtner, C.M., 2011. Social capital and tourism entrepreneurship. Annals of Tourism Research, 38(4), pp.157015

[6] Nonaka, I. \& Takeuchi, H., 1995. The knowledge-creating company: How Japanese companies create the dynamics of innovation,

[7] Bontis, N., 2001. Assessing knowledge assets: a review of the models used to measure intellectual capital. International Journal of Management Reviews, 3(1), pp.41-60.

[8] Bontis, N., 1999. Managing organizational knowledge by diagnosing intellectual capital: framing and advancing the state of the field. International Journal of Technology Management, 18(58), pp.433-462.

[9] Davenport, T., Harris, J. \& Kohli, A., 2001. How do they know their customers so well? MIT Sloan Management Review, 42(2), p.63.

[10] Davenport, T. \& Pruzak, L., 2000. Working knowledge: How organizations manage what they know. The Journal of Technology Transfer, 26(4), pp.396-397. 